\title{
THE ADOPTION OF VIRTUAL LEARNING ENVIRONMENT IN BLENDED CLASSES: AN EMPIRICAL STUDY
}

\author{
Ganesh Vaidyanathan, Roosevelt University,gvaidyanathan@roosevelt.edu
}

\begin{abstract}
A virtual learning environment (VLE) is a web-based platform used in online and hybrid or blended education. VLE allows instructors to publish course information online. Web-based instruction has evolved and so has the process behind the efforts to create, manage, publish, and archive online educational information. This research focuses on finding factors that lead to the adoption of VLE in courses that are offered in hybrid or blended delivery mode. This research proposes a preliminary research model which can be used in the implementations of VLE as well as other platforms that can be classified under similar practices. Based on the data collected, a preliminary analysis reveals that personal traits, such as Information Technology (IT) self-efficacy and attitude toward computer, have positive impacts on VLE adoptions. However, in this preliminary analysis, we also find that social factors, such as the opinions of colleagues, friends and family, do not have significant impact on the adoption decision.
\end{abstract}

Keywords: Virtual Online Environment, adoption, self-efficacy, social factors

\section{INTRODUCTION}

A virtual learning environment (VLE) is a web-based platform. VLE is intended to be used by instructors to present class materials, resources, activities, and interactions to foster positive student learning outcome. Typically, VLE platforms allow creation, storage, access to and use of class resources. They enable instructors in effective curriculum mapping, curriculum planning, and personalization of student learning experiences. VLE should allow students to be organized as teams for groupwork. The platform should have features that can be used for posting quizzes, exams, and other assessments. Student learning progress, achievements, and assessments should be easily achieved using such systems. The platform should also include communication systems such as emails, announcements, chat, live video conferencing, and audio conferencing. A VLE should provide a consistent interface for all courses in every academic program of an institution. This presents all students in the institution a common platform for their learning experiences. This student-centered environment should provide students the flexibility to work in a self-paced format and encourage them to be responsible in their learning. A VLE is required to be a secure platform, available always, and reliable with no loss of personal data.

Many well-known learning environments such as OnCourse, Blackboard, and Moodle are being used in many educational institutions. Many instructors are interested in using VLE to enhance and improve student learning outcomes while combating the reduction in resources in higher education (Pape, 2010). While several studies have positive or no significant effects for student learning outcomes in either online or blended format, there are some studies that found mixed or negative significant effects (Nguyen, 2015). While the ever-rising debate on the effectiveness of online and hybrid learning continues, enrollment in online and hybrid courses rose at a faster pace between fall 2015 and 2016 compared with the previous three years (Friedman, 2018). Therefore, it becomes vital for educators and scholars to understand how such learning environments have been adopted by students. This preliminary study explores the adoption of the VLE in hybrid classes. The next section describes a literature survey followed by a preliminary research model. The following section illustrates a preliminary analysis of the data collected. The last section focuses on conclusion with a discussion on future research.

\section{LITERATURE SURVEY}

Recent research studies have complained that instructors not only do not explore VLE to their full potential but only adopt a limited set of its functionality (Veletsianos, Kimmons, \& French, 2013), and that they do not resort to 


\section{Issues in Information Systems \\ Volume 19, Issue 4, pp. 69-76, 2018}

interactive teaching methods (Christie \& Garrote, 2011). Other research studies have explored various factors that influence faculty decisions in adopting VLEs, including institutional policies (Bennett, Agostinho, Lockyer, Jones, \& Harper, 2011) and pedagogical beliefs (Berggren, Burgos, Fontana, Hinkelman, Hung, Hursh, \& Tielemans, 2005), learning activities (Bennett, Agostinho, \& Lockyer, 2015)), technology effectiveness (Balaam, 2013), and user requirements (Kali, Goodyear, \& Markauskaite, 2011).

There has been a focus on adoption of VLE by instructors as well. In trying to understand the technology acceptance and the role of training. Many instructors do not use the advanced features of VLE but use VLE as a very simple repository for providing students with access to PowerPoint files and reading lists (Rienties, Giesbers, Lygo-Baker, Ma, \& Rees 2016). Such practices do not enhance better learning outcomes (Kinchin, 2012). Rienties et al. (2016) investigated TAM factors on VLE adoption in an experimental, controlled environment. A study by Jenkins, Browne, Walker, \& Hewitt (2010) indicated that the lack of knowledge of VLE is the second highest barrier for technology adoption next to availability of time.

On the perspectives of students, several studies have been accomplished using various extensions of the Technology Acceptance Model (TAM). El-Masri, \& Tarhini (2017) used trust as an external variable in an extended Unified Theory of Acceptance and Use of Technology 2 (UTAUT2) theory to illustrate that performance expectancy, hedonic motivation, habit and trust are significant predictors of behavioral intention. Ong, Lai, \& Wang (2004) introduced a lack of security problems and privacy perception in TAM model. Liu, Chen, Sun, Wible, \& Kuo (2010) included variables such as course design and previous experiences. Ngai, Poon, \& Chan (2007) used technical support as a variable in their model. Persico, Manca, \& Pozzi (2014) adapted TAM to evaluate all the components of the system. The study by Rienties et al. (2016) found that perceived ease-of-use was related to intentions and actual behavior in the use of VLE.

\section{RESEARCH MODEL}

This research is motivated by the need for a proper understanding of the factors leading to the adoption of VLE. We are especially interested in identifying factors and their impact on the adoption decision. As stated in the theory of reasoned action (TRA) by (Ajzen 1980), external variables influence the belief about the outcome of certain behavior, not the behavior itself. Beliefs then in turn shape attitudes toward performing a behavior, which in turn influences the intention to perform the behavior and, ultimately, influences the behavior itself. (Davis 1989) applied these ideas in IT and developed TAM, which is widely used to predict the adoption of IT applications. TAM replaces many of TRA's belief measures with the two technology acceptance measures: ease-of-use, and usefulness, and states that these two measures are the most direct indicators on adoption intention. TAM has been continuously studied and expanded. The two major upgrades being TAM 2 (Venkatesh \& Davis, 2000) and the Unified Theory of Acceptance and Use of Technology (Venkatesh, Morris, Davis, \& Davis, 2003). A TAM 3 has also been proposed in the context of e-commerce with an inclusion of the effects of trust and perceived risk on system use (Venkatesh \& Bala, 2008).

Although TAM states that the influences of all other variables on technology acceptance outcomes is mediated by individual beliefs about technology use, more work is needed to understand the determinates of beliefs (Agarwal \& Prasad, 1999; Venkatesh \& Davis, 2000) and the role of attitude. To help to understand the adoption of VLE, our research model presented in Figure 1 extends TAM by adding the attitude construct and two sources of influence on beliefs: personal factors and social factors.

In our research model, we employ perceived usefulness (PU) and perceived ease-of-use (PEOU) as antecedents of intention of use and attitude as explained by $\mathrm{Hu}$, Chau, Sheng, and Tam (1999). Perceived usefulness is the degree to which a person believes that using a system would enhance his or her job performance and perceived ease-of-use is the degree to which a person believes that using a system would be free from effort (Davis 1989). In this preliminary model, we posit four different factors including informal social circle, external social circle, personal innovativeness, and self-efficacy to act as independent variables that can impact PU and PEOU. Personal factors have the most important influence of individual's cognitive interpretations of information technology. In IT literature, two constructs have been consistently considered as important predictors of personal beliefs: computer 


\section{Issues in Information Systems}

Volume 19, Issue 4, pp. 69-76, 2018

self-efficacy and personal innovativeness. Computer self-efficacy refers to individuals' judgment of their capabilities to use computers in diverse situations (Compeau \& Higgins, 1995; Marakas, Yi, \& Johnson, 1998).

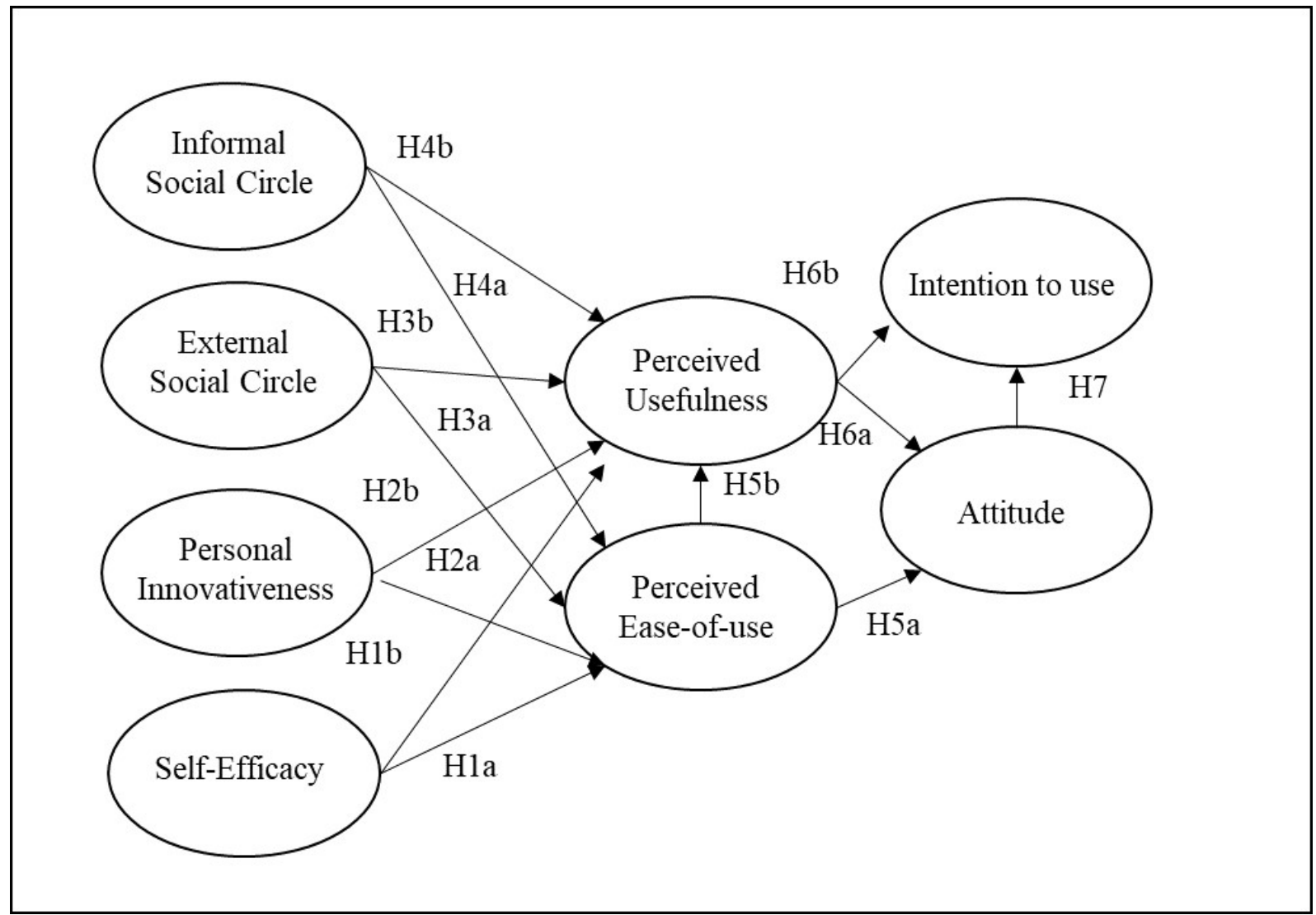

Figure 1. Research Model

Previous research has suggested that individuals with high level of computer self-efficacy tend to have more positive perceptions of IT (Venkatesh \& Davis, 1996). Personal innovativeness measures individuals' willingness to change (Hurt Joseph, \& Cooed, 1977). It is believed to be related to individuals' tolerance of risk, because if individuals are more willing to take risks, they are more likely to engage in innovative behavior (Agarwal \& Prasad, 1998a; Bommer \& Jalajas, 1999). Personal innovativeness with IT have received a lot of attentions in the literature, and many studies have shown that individuals with high level of personal innovativeness are more likely to have confidence in using new technology (Agarwal \& Prasad, 1998b; Agarwal \& Karahanna, 2000). Following the above research, the following hypotheses are tested in this paper:

H1a: Self efficacy has positive impact on perceived ease-of-use of VLE.

H1a: Self efficacy has positive impact on perceived usefulness of VLE.

H2a: Personal innovativeness has positive impact on perceived ease-of-use of VLE.

$\mathrm{H} 2 \mathrm{~b}$ : Personal innovativeness has positive impact on perceived usefulness of VLE.

A lot of research have been done in the IS literature to study the influence of social factors on technology adoption as well. Social psychology theory defines subjective norm as perceived social pressure to perform or not perform the behavior. (Mathieson, 1991; Thompson Higgins, \& Howell, 1991; Taylor \& Todd, 1995). Social information processing theory states that information conveyed via individuals' social networks influences their cognition about a target technology (Schmitz, 1991; Fulk, 1993). Following these ideas, we created the concept of a local circle and an extended circle. The local circle refers to peers, such as the opinions of friends and colleagues in school or university. These are the people an individual meets every day at school or university, who tend to have a stronger 
impact on adoption decisions due to their everyday involvement. The extended circle refers to friends and family, the informal circle outside one's university environment. An individual might consult the extended circle for advice but less frequently, so apparently their impact is weaker than those from the local circle. We test the following hypotheses regarding social factors:

H3a: Extended social circle has positive impact on perceived ease-of-use of VLE.

$\mathrm{H} 3 \mathrm{~b}$ : Extended social circle has positive impact on perceived usefulness of VLE.

$\mathrm{H} 4 \mathrm{a}$ : Informal social circle has positive impact on perceived ease-of-use of VLE.

H4b: Informal social circle has positive impact on perceived usefulness of VLE.

Perceived ease-of-use focuses on the cultural reaction to VLE. Introducing a new system to a college or university can shock many students and cause a difficult learning curve for both the faculty and students. The perception of how the new system will work can affect how it eventually gets accepted into the organization. If a system is seen as being complex and confusing, then it will not fit into many organizations and should ultimately not be implemented. In the context of IT, previous research has shown that beliefs about the outcome of using the system will shape the attitude toward using and adopting, which will in turn influence the behavioral intention(Ajzen \& Fishbein, 1980; Agarwal \& Prasad, 1998a; Compeau, Higgins, \& Huff, 1999). We thus followed the previous research by studying the following two hypotheses:

H5a: Perceived ease-of-use has positive impact on attitude toward VLE.

H5b: Perceived ease-of-use has positive impact on perceived usefulness of VLE.

H6a: Perceived usefulness has positive impact on attitude toward VLE.

H6b: Perceived usefulness has positive impact on the intention to use the system.

H7: Attitude toward the system has positive impact on the intention to use the system.

\section{PRELIMINARY DATA ANALYSIS}

In this section, a preliminary data analysis along with data gathering analysis is presented. To assess the adoption of VLE in an academic institution, we solicited participation from graduate students who used a popular VLE called Oncourse. Invitations to participate in the survey were sent to the graduate students by email. The URL to the webbased questionnaire using Qualtrics, an online survey platform, was included in the email. If the individuals agreed to participate in the study, they could just follow the URL and answer the survey questions. To avoid double entries, IP addresses were logged and inputs from the same IP were eliminated. A total of 128 individuals participated in the survey. Each participant filled out a brief survey of demographic and computer usage information. Our final usable sample consisted of 96 complete and valid responses. The age of respondents varied from 25 years to 42 years. Of these, 36 percent were female and 64 percent male. Years of using computers range from no experience to 6 years. Experiences with VLE varied from no experience to 6 years. A clear majority of the respondents had prior experience with various VLE platforms.

\section{Data and Research Method}

Most of the constructs employed in the study were assessed through seven-point Likert scale survey questions derived from published literature. Following (Lewis, Agarwal, \& Sambamurthy, 2003), two sources of social influence on peoples' perception of VLE were studied in this paper: Informal Circle and Extended Circle. These factors were assessed using an expectancy formulation with a pair of items for each source that were multiplied to yield the final social influence score for each referent. One item tapped into the extent to which the referent other would view use of the VLE favorably, while the second measured the respondent's motivation to comply with the wishes of the referent other. Such an expectancy formulation of social influence is a widely accepted operation for this kind of construct (Ajzen \& Fishbein, 1980; Taylor \& Todd, 1995). We did not study the organizational factors because the focus of this project is on VLE adoption decisions for personal educational uses.

Three individual factors of personal Innovativeness, self-efficacy and attitude toward VLE were also studied. Scales and items used to measure these factors were adapted from (Hurt et al., 1977; Agarwal \& Prasad, 1998a; Bommer \& Jalajas, 1999; Agarwal \& Karahanna, 2000; Lewis et al., 2003; Compeau \& Higgins, 1995); Nickell \& Pinto, 1986). 
Finally, perceived usefulness, perceived ease-of-use and intention to use were assessed by three-item scales derived from (Davis, 1989; Moore \& Benbasat, 1991). These items have been used and validated in numerous previous researches and are considered reliable and consistent.

\section{Analysis}

Ghiselli, Campbell, \& Zedeck (1981) presented two tests of divergent validity. The first test involved ensuring that the item-to-scale correlations of the items not in the scale be generally lower than those for the items in the scale. The second test involved a comparison of the reliabilities of the scales employed with the inter-scale correlations. For a scale to demonstrate adequate divergent validity, the reliability of the scale must be significantly higher than its correlation with other scales. Both tests indicated sufficient divergent validity for the scales for sources of influences and Technology Acceptance constructs.

We present correlations between the constructs employed in the study in Table 1. Several significant correlations can be observed. The correlations between Perceived Usefulness and social factors (Informal Circle and Extended Circle) were statistically significant. The correlations between Perceived Ease-of-use and Personal Innovativeness, and Perceived Ease-of-use and Attitude toward Computing were also significant, while the correlation between Perceived Ease-of-use and Self Efficacy was surprisingly not significant. We also observe that Intention to Use was significantly correlated with Perceived Usefulness, Perceived Ease-of-use, and Attitude toward Computing.

Table 1. Correlations among Study Constructs

\begin{tabular}{llllllllll}
\hline & Variables & $\mathbf{1}$ & $\mathbf{2}$ & $\mathbf{3}$ & $\mathbf{4}$ & $\mathbf{5}$ & $\mathbf{6}$ & $\mathbf{7}$ & $\mathbf{8}$ \\
\hline 1 & Perceived Usefulness & 1.00 & & & & & & & \\
2 & Perceived Ease-of-use & $0.64^{*}$ & 1.00 & & & & & & \\
3 & Informal Circle & 0.18 & 0.25 & 1.00 & & & & & \\
4 & Extended Circle & 0.21 & 0.18 & $0.74^{*}$ & 1.00 & & & & \\
5 & Personal Innovativeness & $0.55^{*}$ & $0.49^{* *}$ & 0.39 & 0.35 & 1.00 & & & \\
6 & Self-efficacy & 0.22 & $0.38^{* *}$ & 0.08 & 0.09 & $0.52^{*}$ & 1.00 & & \\
7 & Attitude toward VLE & $0.78^{*}$ & $0.82^{*}$ & 0.12 & 0.15 & $0.65^{*}$ & $0.63^{*}$ & 1.00 & \\
8 & Intention to Use & $0.76^{* *}$ & $0.61^{* *}$ & 0.18 & 0.24 & $0.54^{*}$ & $0.35^{*}$ & $0.59^{*}$ & 1.00 \\
\hline
\end{tabular}

\section{CONCLUSION, LIMITATIONS, AND FUTURE RESEARCH}

TAM provides a theory towards how users accept and use new technology. The preliminary analysis investigates both perceived usefulness and perceived ease-of-use but fails to see the full picture which includes social and personal factors. Perception of a new technology sets a standard for the regard given to the system from the initial adoption phase. A user's perception is determined based on specific environments surrounding the implementation. This has lead us to our new model which makes a detailed investigation into the adoption of a VLE platform by questioning the social and individual development environments that will surround the adoption of a new system. This goes beyond a simple investigation of whether a new technology will be used to understand not only whether it will be used, but whether it will be accepted by the developers, users, and peers. Personal traits of the developers designated as "attitude" will provide a direct correlation with system selection.

Perceived ease-of-use, perceived usefulness, individual factors, and social factors are the four variables that most directly impact a VLE adoption. In our preliminary analysis, our data supports hypotheses 1,2 , and 5 . In this preliminary analysis, $\mathrm{H} 3 \mathrm{a}, \mathrm{H} 3 \mathrm{~b}, \mathrm{H} 4 \mathrm{a}$, and $\mathrm{H} 4 \mathrm{~b}$ are not supported. However, this preliminary study has shown the process of a personal VLE adoption. With this simple finding, the next step is to continue our research to investigate this research model further.

We plan to acquire additional data to take a closer look into social factors that may pose as antecedents to TAM. The data that we collected may not be enough to predict relationships of social factors to TAM and the attitude factor that we are expecting to extend the TAM model. We did not conduct factor analysis and Since correlations provide 


\section{Issues in Information Systems \\ Volume 19, Issue 4, pp. 69-76, 2018}

only preliminary insights, we need to obtain results using a structural equation model (SEM) analysis on the research model. SEM is a second-generation estimation technique and enables researchers to address a set of interrelated research questions in a single, systematic, and comprehensive analysis by modeling relationships between multiple independent and dependent variables simultaneously. SEM has been widely applied in the information systems, social sciences and marketing literature.

Our practical implications are that personal factors will be more significant in VLE adoption than the social factors. This falls back on the more general idea of a system environment. A personal adoption will be affected by the personal attitude and surroundings of the system. It is theorized that a larger organizational implementation will then take more of an effect from the social and institutional factors of the system adoption. We believe that social factors will come into play when we investigate this model further.

\section{REFERENCES}

Agarwal, R., \& Karahanna, E. (2000). Time flies when you're having fun: cognitive absorption and beliefs about information technology usage. MIS Quarterly, 24(4), 665-694.

Agarwal, R., \& Prasad, J. (1998a). The antecedents and consequents of user perceptions in information technology adoption. Decision Support Systems, 22, 15-29.

Agarwal, R., \& Prasad, J. (1998b). A conceptual and operational definition of personal innovativeness in the domain of information technology. Information Systems Research, 9(2), 204-215.

Agarwal, R., \& Prasad, J. (1999). Are Individual Differences Germane to the Acceptance of Information Technologies? Decision Sciences, 30(2), 361-391.

Ajzen, I., \& Fishbein, M. (1980). Understanding Attitudes and Predicting Social Behavior. Englewood Cliffs, NJ: Prentice-Hall, Inc.

Balaam, M. (2013). A Part Practical and Part Conceptual Response to Orchestration. Computers and Education, 69 , 517-519.

Bennett, S., Thomas, L., Agostinho, S., Lockyer, L., Jones, J., \& Harper, B. (2011). Understanding the design context for Australian university teachers: implications for the future of learning design. Learning, Media and Technology, 36(2), 151-167.

Bennett, S., Agostinho, S., \& Lockyer, L. (2015). Technology tools to support learning design: Implications derived from an investigation of university teachers' design practices. Computers and Education, 81, 211-220.

Berggren, A., Burgos, D., Fontana, J. M., Hinkelman, D., Hung, V., Hursh, A. \& Tielemans, G. (2005). Practical and pedagogical issues for teacher adoption of IMS Learning Design standards in Moodle LMS. Journal of Interactive Media in Education, 2(2), 1-24.

Bommer, M., \& Jalajas, D. S. (1999). The threat of organizational downsizing on the innovative propensity of R\&D professionals. R\&D Management, 29(1), 27-34.

Christie, M., \& Garrote, R.J. (2011). Lecturer engagement in the use of interactive tools in learning management systems. A Swedish case study. In: Proceedings of the Australasian Society for Computers in Learning in Tertiary Education Conference (ASCILITE '11), Hobart, Australia.

Compeau, D. R., Higgins, C. A., \& Huff, S. (1999). Social cognitive theory and individual reactions to computing technology: A longitudinal study. MIS Quarterly, 23(2), 145-158.

Compeau, D., \& Higgins, C. (1995). Computer self-efficacy: development of a measure and initial test. MIS Quarterly, 19, 189-211. 


\section{Issues in Information Systems}

Volume 19, Issue 4, pp. 69-76, 2018

Davis, F. D. (1989). Perceived usefulness, perceived ease of use, and end-user acceptance of information technology. MIS Quarterly, 13(3), 318-339.

El-Masri, M., \& Tarhini, A. (2017). Factors affecting the adoption of e-learning systems in Qatar and USA: Extending the Unified Theory of Acceptance and Use of Technology 2 (UTAUT2). Educational Technology Research and Development, 65(3), 743-763.

Freidman, J. (2018). More students are enrolling in online courses. Retrieved from https://www.usnews.com/highereducation/online-education/articles/2018-01-11/study-more-students-are-enrolling-in-online-courses on May 2018.

Fulk, J. (1993). Social construction of communication technology. Academy of management journal, 36(5), 921950.

Ghiselli, E. E., Campbell, J. P., \& Zedeck S. (1981). Measurement Theory for the Behavioral Sciences. San Francisco: W.H. Freeman.

Hu, P. J., Chau, P. Y., Sheng, O. R. L., \& Tam, K. Y. (1999). Examining the technology acceptance model using physician acceptance of telemedicine technology. Journal of management information systems, 16(2), 91112.

Hurt, H. T., Joseph, K., \& Cooed, C.D. (1977). Scales for the measurement of innovativeness. Human Communication Research, 4,58-65.

Jenkins, M., Browne, T., Walker, R., \& Hewitt, R. (2010). The development of technology enhanced learning: findings from a 2008 survey of UK higher education institutions. Interactive Learning Environments, $19(5), 447-465$.

Kali, Y., Goodyear, P., \& Markauskaite, L. (2011). Researching design practices and design cognition: contexts, experiences and pedagogical knowledge-in-pieces. Learning, Media and Technology, 36(2), 129-149.

Lewis, W., Agarwal, R., \& Sambamurthy, V. (2003). Sources of Influence on Beliefs about Information Technology Use: An Empirical Study of Knowledge Workers. MIS Quarterly, 27(4), 657-678.

Liu, I. F., Chen, M. C., Sun, Y. S., Wible, D. \& Kuo, C. (2010). Extending the TAM model to explore the factors that affect Intention to Use an Online Learning Community. Computers and Education, 54, 600-610.

Marakas, G. M., Yi, M. Y., \& Johnson, R. D. (1998). The multilevel and multifaceted character of computer selfefficacy: Toward clarification on the construct and an integrative framework for research. Information Systems Research 9(2), 126-163.

Mathieson, K. (1991). Predicting user intentions: Comparing the technology acceptance model with the theory of planned behavior. Information Systems Research 2(3), 173-191.

Moore, P. R., \& Benbasat, I. (1991). Development of an Instrument to Measure the Perceptions of Adopting an Information Technology Innovation. Information Systems Research 2(3), 192-222.

Ngai, E., Poon, J. \& Chan, Y. (2007). Empirical examination of the adoption of WebCT using TAM. Computers and Education, 48, 250-267.

Nguyen, T. (2015). The Effectiveness of Online Learning: Beyond No Significant Difference and Future Horizons. MERLOT. Journal of Online Learning and Teaching, 11(2), 309-319.

Nickell, G. S., \& Pinto, J. N. (1986). The computer attitude scale. Computers in Human Behavior, 2, 3031-306. 


\section{Issues in Information Systems}

Volume 19, Issue 4, pp. 69-76, 2018

Ong, C., Lai, J. \& Wang, Y. (2004). Factors affecting engineers' acceptance of asynchronous e-learning system in high-tech companies. Information and Management, 41, 795-804.

Pape, L. (2010). Blended Teaching \& Learning. School Administrator, 67(4), 16-21.

Persico, D., Manca, S. \& Pozzi, F. (2014). Adapting the Technology Acceptance Model to evaluate the innovative potential of e-learning systems. Computers in Human Behavior, 30, 614-622.

Rienties, B., Giesbers, B., Lygo-Baker, S., Ma, H. W. S., \& Rees, R. (2016). Why some teachers easily learn to use a new virtual learning environment: a technology acceptance perspective. Interactive Learning Environments, 24(3), 539-552.

Schmitz, J. F., \& Fulk, J. (1991). Organizational colleagues, media richness, and electronic mail: A test of the social influence model of technology use. Communication Research, 18(4), 487-523.

Taylor, S., \& Todd, P. (1995). Accessing IT Usage: The Role of Prior Experience. MIS Quarterly, 19(4), 561.

Thompson, R. L., Higgins, C. A., \& Howell, J. M. (1991). Personal computing: Toward a conceptual model of utilization. MIS Quarterly, 15(1), 125-144.

Veletsianos, G., Kimmons, R., \& French, K.D. (2013). Instructor Experiences with a Social Networking Site in a Higher Education Setting: Expectations, Frustrations, Appropriation, and Compartmentalization. Education Technology Research Development, 61, 255-278.

Venkatesh, V., \& Bala, H. (2008). Technology acceptance model 3 and a research agenda on interventions. Decision sciences, 39(2), 273-315.

Venkatesh, v., Morris, M.G., Davis, G.B., \& Davis, F.D. (2003). User Acceptance of Information Technology: Toward a Unified View. MIS Quarterly, 27(3), 425-478.

Venkatesh, V., \& Davis, F. D. (2000). A Theoretical Extension of the Technology Acceptance Model: Four Longitudinal Field Studies. Management Science 46(2), 186-204.

Venkatesh, V., \& Davis, F. D. (1996). A model of the antecedents of perceived ease of use: Development and test. Decision Sciences, 27(3), 451-482. 